\title{
Hard Magnetization Direction and Its Relation with Permeability of Conventional Grain-oriented Electrical Steel
}

\author{
Li Changsheng, Wang Hao, Zhu Tao
}

State Key Laboratory of Rolling and Automation, Northeastern University, Shenyang 110819, China

\begin{abstract}
Magnetic properties of conventional grain-oriented electrical steel sheets are different in various directions. In the present paper, Epstein standard samples were cut with different angles to rolling direction, and the corresponding magnetic properties of samples were tested. Results show that the hard magnetization direction to the rolling direction is around $60^{\circ}$. Conventional elliptical models are not accurate to simulate permeability at all magnetic intensities, and parabolic and hybrid models with high accuracy are proposed to simulate relations between permeability and magnetization direction. When magnetic intensity is no less than 10000 $\mathrm{A} / \mathrm{m}$, hybrid model can be used, and when magnetic intensity is less than $10000 \mathrm{~A} / \mathrm{m}$, parabolic model should be applied. Two-stage relation model of permeability and magnetization angles is of significance in improving the accuracy of electromagnetic engineering calculations of electrical steel and can be applied in industrial applications.
\end{abstract}

Key words: hard magnetization direction; conventional grain-oriented electrical steel; permeability model; parabolic and hybrid models; magnetic intensity

Conventional grain-oriented (CGO) electrical steel is widely used in electrical transformers, voltage regulators and electromagnetic switches as a kind of significant soft magnetic materials ${ }^{[1,2]}$. The growing worldwide demands for efficient electrical power generation and distribution equipments are significant drivers for the rapid development of steels with lower power loss and higher permeability. Distribution calculation of power loss and magnetic fields is closely related to the magnetic parameters of the materials; therefore, it is necessary to carry out further research on simulation of magnetic parameters $^{[3-5]}$. Magnetic properties simulation is based on magnetization process, and the orientation of the grain-oriented electrical steel and the rolling process parameters are strongly related ${ }^{[6-11]}$. Only magnetic parameters in easy and hard magnetization directions are usually provided by manufacturers, but some scholars pointed out that simulation results by two directional parameters are not accurate enough.

Some research showed that for CGO electrical steel the hard magnetization direction was not perpendicular to the rolling direction, and they proposed elliptic curve models to simulate the steel magnetization, but did not achieve ideal simulation results ${ }^{[12-15]}$. So far, multidimensional magnetic measuring instruments have been developed, which can obtain relatively accurate magnetic measurements, but its application is limited to specialized research institutions, and data processing is discommodious, bringing inconvenience to the next-step simulation ${ }^{[16-19]}$. Epstein test method is still the most widely applied and valuable method for testing magnetic properties of grain-oriented electrical steel $^{[20]}$. Epstein samples with different angles to the rolling direction were cut and magnetized. On the basis of experimental data, conventional elliptical model was

Received date: June 28, 2015

Foundation item: National Natural Science Foundation of China (51174057, 51274062); the National High Technology Research and Development Program (2012AA03A503)

Corresponding author: Li Changsheng, Ph. D., Professor, State Key Laboratory of Rolling and Automation, Northeastern University, Shenyang 110819, P. R. China, Tel: 0086-24-83687749, E-mail: lics@ ral.neu.edu.cn

Copyright $($ C 2016, Northwest Institute for Nonferrous Metal Research. Published by Elsevier BV. All rights reserved. 
modified as parabolic and hybrid models in the present paper. The accuracy of new models proposed was examined, and model applications were also discussed.

\section{Experiment}

Fe-3\%Si CGO electrical steel samples were applied in the present paper, and the nominal chemical composition (wt\%) of electrical steel was $3.05 \mathrm{Si}, 0.15 \mathrm{Mn}, 0.04 \mathrm{Cu}, 0.03 \mathrm{C}$, 0.03Al, 0.02N, Bal. Fe.

Standard Epstein samples were used to measure the magnetic characteristics of grain-oriented electrical steel, and relative cutting angles of the samples to the rolling direction were $90^{\circ}, 75^{\circ}, 60^{\circ}, 45^{\circ}, 30^{\circ}, 15^{\circ}$ and $0^{\circ}$, respectively. As shown in Fig.1, $\alpha$ is a representative of the angle to the rolling direction.

MST-300 AC magnetic measurement apparatus was applied to measure magnetic properties of tested Epstein samples. Each sample was tested three times and then averaged, and every three samples in the same direction were tested and then averaged. Samples were taken out and demagnetized to eliminate remanence before next measurement. Magnetization parameters with different angles to the rolling direction were gained.

\section{Results and Discussion}

2.1 Coordinate decomposition of magnetic induction and determination of hard magnetization angle

During measurement process, magnetic intensity $H$ is along the direction with magnetic induction vector $B$, whose relation curves of CGO electrical steel were drawn and are shown in Fig. 2 according to experimental data.

Vector $B$ could be resolved into two orthogonal components $B_{x}$ and $B_{y}$ according to Eq.(1).

$$
\left\{\begin{array}{l}
B_{x}=B \cos (\alpha) \\
B_{y}=B \sin (\alpha)
\end{array}\right.
$$

Magnetic induction could be resolved as $B_{x}$ and $B_{y}$ as Eq.(1), and its relation with magnetic intensity is shown in Fig.3a.

Measured results of permeability variation with different magnetization angles are shown in Fig.3b. As can be seen from the figure, permeability at low magnetization angle

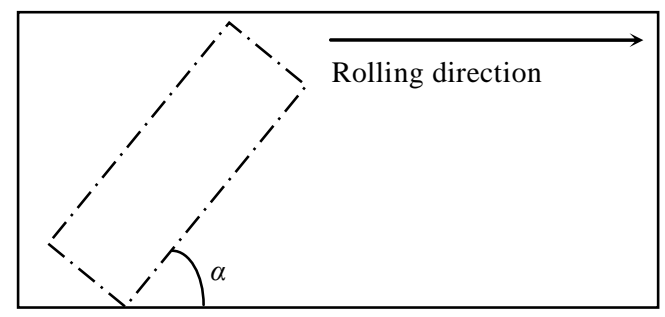

Fig.1 Cutting angle to the rolling direction

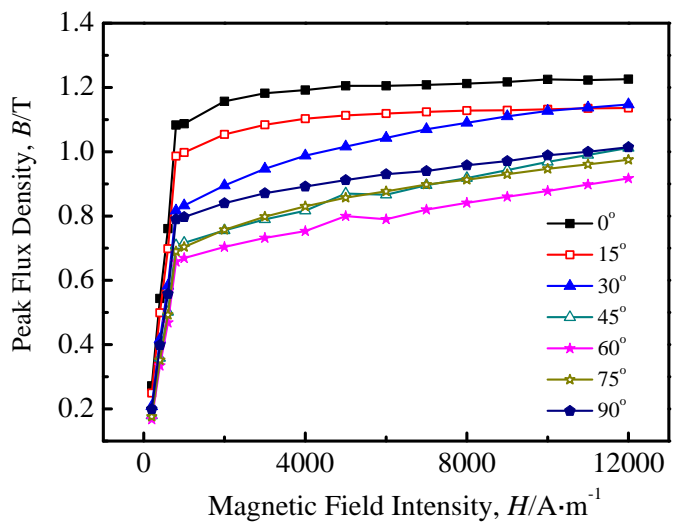

Fig.2 Multidirectional $B$ - $H$ curves of CGO electrical steel
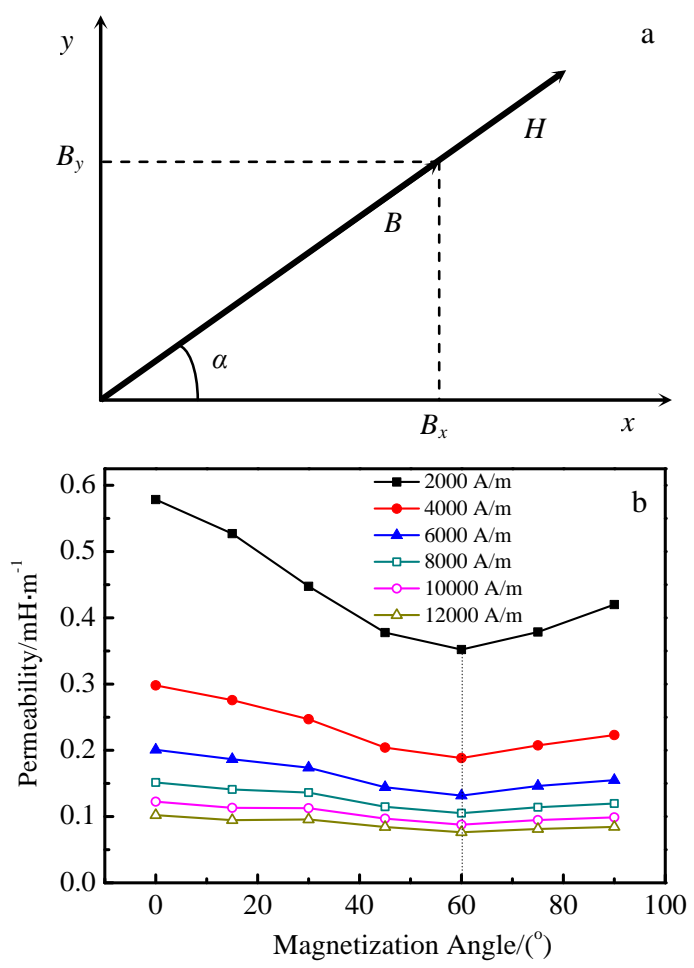

Fig.3 Coordinate decomposition of magnetic induction (a) and determination of hard magnetization angle (b)

drops much and that at high magnetization angle rises slightly. Permeabilities at different magnetic intensities reach the bottom at around $60^{\circ}$ to the rolling direction, which is regarded as hard magnetization point in the present paper. The hard magnetization direction to the rolling direction is near $60^{\circ}$. With the increase of magnetization angle, permeability first declines sharply and levels off above $60^{\circ}$.

\subsection{Inconformity of conventional elliptical permeability models}

Magnetization simulation is based on both magnetization curves in rolling direction $\left(\alpha=0^{\circ}\right)$ and perpendicular to 
rolling direction $\left(\alpha=90^{\circ}\right)$. After calculation by applying mathematical models, magnetization curves could be drawn in different directions. Z. Cheng et al used elliptical permeability model $^{[21]}$, and the model is given by Eq.(2),

$$
\frac{B_{x}^{2}}{\mu_{x 0}^{2}}+\frac{B_{y}^{2}}{\mu_{y 0}^{2}}=H^{2}
$$

where $\mu_{y 0}$ and $\mu_{x 0}$ are permeability at the same magnetic intensity in two curves with corresponding $\alpha=0^{\circ}$ and $\alpha=$ $90^{\circ}$, respectively.

As permeability $\mu$ is the ratio of magnetic induction to magnetic intensity, permeability could be expressed as Eq.(3),

$$
\mu=\frac{\mu_{x 0} \mu_{y 0}}{\sqrt{\mu_{x 0}^{2} \sin ^{2} \alpha+\mu_{y 0}^{2} \cos ^{2} \alpha}}
$$

Eq.(3) shows that the permeability of CGO electrical steel depends not only on initial magnetic parameters, but also on magnetization angles. Relations between the permeability and the magnetization angle are shown in Fig.4. From the comparison of ellipsoidal fitting curves and measured curves it is obvious that at both high and low magnetic intensities the fitting degree is low, and there is an obvious gap between model curve and measured curve, which indicates that ellipsoidal model curves is not suitable to simulate the relation between the permeability and magnetization the angle. Therefore, it is necessary to build new models. On the simulative curve the hard magnetization direction is still perpendicular to the rolling direction. With the rise of magnetization angle the permeability tends to fall gradually, but the measured hard magnetization direction to the rolling direction is around $60^{\circ}$, which also shows that it is inaccurate to simulate magnetic properties upon applying the elliptical model at different magnetic intensities.

There exists the obvious hard magnetization direction in grain-oriented electrical steel. The magnetization direction and the magnetic permeability are closely related, which is mainly due to the strong magnetic anisotropy of electrical steel. When the external magnetic field uniformly magnetizes electrical steel along a certain magnetization direction, the distribution of magnetic field lines would have preferred orientation. Along the direction of the magnetic permeability a priority to fill magnetic field lines will be given, and for the experimental electrical steels the direction is the rolling direction. However, as the relative magnetic permeability of the magnetization process will reach its peak value, the steel is also filled with the saturated magnetic field lines, which corresponds to the state of the shielding effectiveness peak. With increasing of the external magnetic field intensity, the relative magnetic permeability along the rolling direction is gradually attenuated and the steel is also filled with the magnetic field lines in the other directions, which is similar to the filling process of the rolling direction. As magnetic permeabilities in other directions will also reach the maximum values, relative magnetic permeability in the rolling direction is smaller than that in other directions. Therefore, as the peak point appears, attenuation speed of magnetic permeability
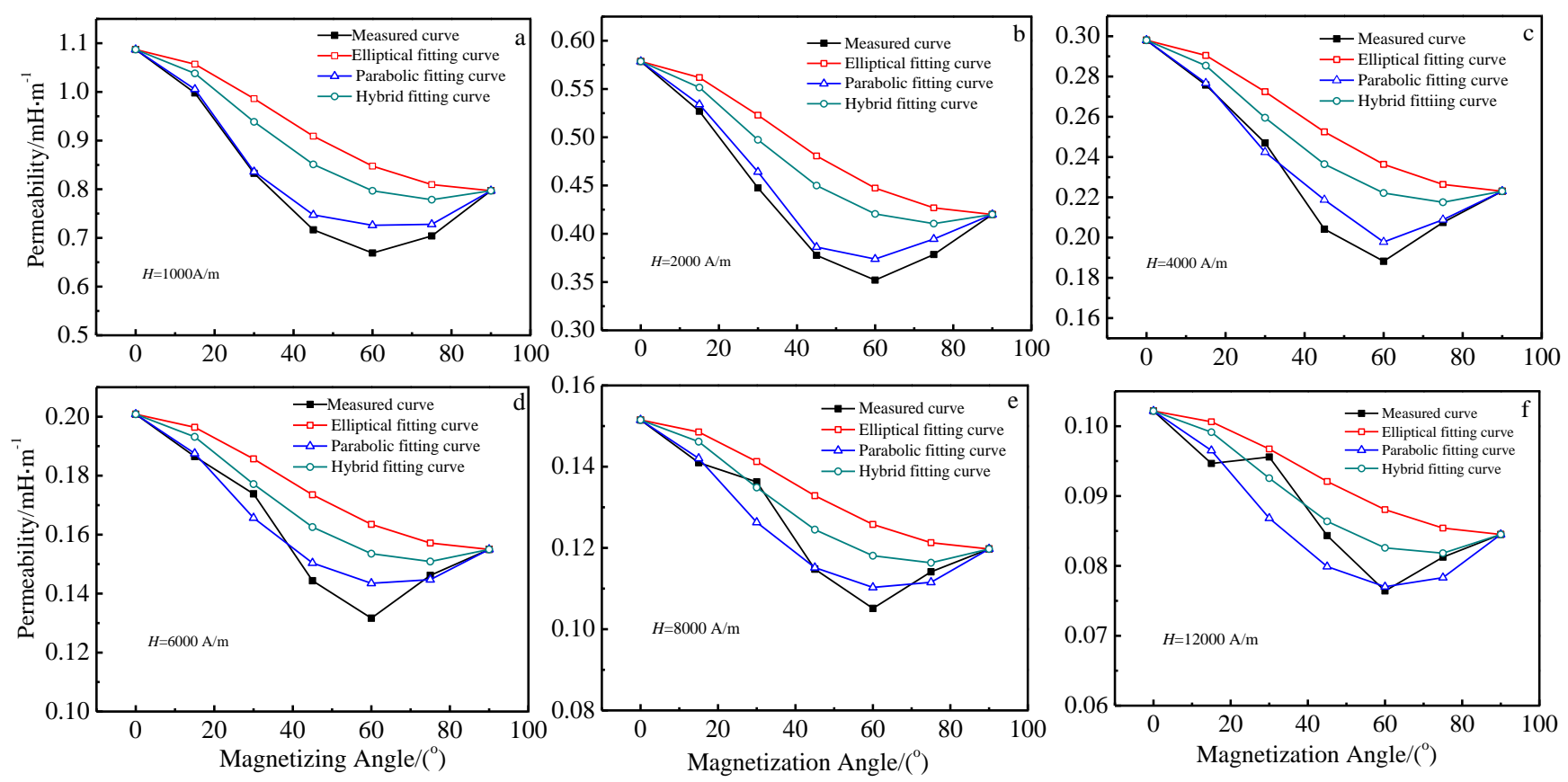

Fig.4 Measured, elliptical, parabolic and hybrid permeability fitting variation with magnetization angle at different magnetic intensities: (a) $H=1000 \mathrm{~A} / \mathrm{m}$, (b) $H=2000 \mathrm{~A} / \mathrm{m}$, (c) $H=4000 \mathrm{~A} / \mathrm{m}$, (d) $H=6000 \mathrm{~A} / \mathrm{m}$, (e) $H=8000 \mathrm{~A} / \mathrm{m}$, and (f) $H=12000 \mathrm{~A} / \mathrm{m}$ 
with the magnetic flux density does not increase significantly. Similarly, the magnetic lines during the filling process could also be viewed at different angles of magnetization, which can be interpreted as a certain angle when the maximum energy is required for the magnetization process. The hard magnetization direction occurs while the magnetic permeability reaches its minimum value.

\subsection{Hard magnetization direction determined by parabolic and hybrid permeability}

As elliptic permeability model is inaccurate, parabolic permeability models were proposed by authors, as shown in Eq.(4).

$$
\frac{B_{x}}{\mu_{x 0}} H+\frac{B_{y}^{2}}{\mu_{y 0}^{2}}=H^{2}
$$

Permeability could be calculated as Eq.(5) derived from Eq.(4).

$$
\boldsymbol{\mu}=\left\{\begin{array}{l}
\frac{\mu_{y 0}\left(\sqrt{4 \mu_{x 0}^{2} \sin ^{2} \alpha+\mu_{y 0}^{2} \cos ^{2} \alpha}-\mu_{y 0} \cos \alpha\right)}{2 \mu_{x 0} \sin ^{2} \alpha}(\alpha \neq 0) \\
\mu_{y 0}(\alpha=0)
\end{array}\right.
$$

Permeability variation with magnetization angle at a certain intensity was drawn. As can be seen from Fig. 4, at low magnetic intensity the fitting degree is high, but as magnetic intensity exceeds $10000 \mathrm{~A} / \mathrm{m}$ the gap between model curve and measured curve emerges. When magnetic intensity is above $10000 \mathrm{~A} / \mathrm{m}$, measured curve fluctuates between elliptical and parabolic fitting curve. Therefore, it is necessary to build a hybrid model whose value is between two fitting curves in Fig. 4.

After process and analysis of sufficient experimental data, authors have found that when magnetic intensity is above $10000 \mathrm{~A} / \mathrm{m}$, both the parabolic and elliptical models are not accurate enough. Therefore, a hybrid permeability model could be established as shown in Eq.(6).

$$
\frac{1}{2}\left(\frac{B_{x}^{2}}{\mu_{x 0}^{2}}+H \frac{B_{x}}{\mu_{x 0}}\right)+\frac{B_{y}^{2}}{\mu_{y o}^{2}}=H^{2}
$$

Permeability depends on magnetization direction and initial magnetic parameters, which can be written as Eq. (7) when magnetic intensity is above $10000 \mathrm{~A} / \mathrm{m}$.

$$
\mu=\frac{\mu_{x 0} \mu_{y 0}\left(\sqrt{16 \mu_{x 0}^{2} \sin ^{2} \alpha+9 \mu_{y 0}^{2} \cos ^{2} \alpha}-\mu_{y 0} \cos \alpha\right)}{2\left(2 \mu_{x 0}^{2} \sin ^{2} \alpha+\mu_{y 0}^{2} \cos ^{2} \alpha\right)}
$$

The appropriate models and the relations between magnetization angle and permeability have been built, and $\mu-\alpha$ curve could be drawn. Different models were compared as shown in Fig.4. On the basis of the experimental data at different magnetic intensities, after comparison we could find that the hard magnetization direction to the rolling direction is around $60^{\circ}$. Except hard magnetization angle, other angle regions could be well simulated and the fitting degree is high. At regions around $60^{\circ}$, the measured permeability is lower than simulated permeability.

For both hybrid and elliptical models, it is noticeable that near hard magnetization region, fitting magnetic permeability is higher than measured data. However, it is still appropriate to apply permeability and magnetization relation models to calculate hard magnetization angle. When fixed magnetization angle is given, related permeability could be calculated, and when using hybrid models, permeability calculation should be referred to parabolic models at hard magnetic zone to achieve high fitting degree, which could refer to Eq.(5).

Since anisotropic magnetic properties are complex in CGO electrical steel, it is essential to optimize electromagnetic models including multidirectional permeability models built above to reduce energy consumption and optimize the design of the overall performance of transformers, which is of significance in numerical electromagnetic analysis of electrical steel for its industrial application.

\section{Conclusions}

1) Hard magnetization direction of CGO electrical steel is not perpendicular to the rolling direction, but with an angle of around $60^{\circ}$ to the rolling direction. With rise of magnetization angle, permeability first drops sharply and levels off above $60^{\circ}$.

2) Conventional elliptical models are not accurate to simulate permeability at all magnetic intensities. Parabolic and hybrid models with high accuracy which were proposed to simulate relations between permeability and magnetization direction have been built. When magnetic intensity is less than $10000 \mathrm{~A} / \mathrm{m}$, parabolic model should be applied, and when magnetic intensity is no less than $10000 \mathrm{~A} / \mathrm{m}$, hybrid model could be used.

3) Two-stage models could be applied with initial magnetic parameters, and when magnetization angle is near hard magnetization angle, permeability calculation with elliptical and hybrid models should refer to parabolic model to achieve high fitting degree.

\section{References}

1 Kumano T, Ushigami Y. ISIJ International[J], 2007, 47: 890

2 Wang H, Li C S, Zhu T et al. Journal of Materials Science and Technology[J], 2013, 29: 673

3 Barros J, Schneider J, Verbeken K et al. Journal of Magnetism and Magnetic Materials[J], 2008, 320: 2490

4 Zhu Z H, Yin L, Hu Q et al. Rare Metal Materials and Engineering[J], 2014, 43(4): 1037 (in Chinese)

5 Fujisaki K, Tamaki T. IEEE Transactions on Magnetics [J], 2009, 45: 687 
6 Cheng Z, Takahashi N, Forghani B et al. IEEE Transactions on Magnetics[J], 2014, 50: 630

7 Moradi H, Afjei E. Electrical Engineering[J], 2014, 96: 15

8 Pongsakorn J, Jureeporn N, Chitnarong S. Rare Metal Materials and Engineering[J], 2013, 42(1): 19 (in Chinese)

9 Bertand C, Ssmuel L, Francois B J et al. Surface and Coatings Technology[J], 2014, 47: 1

10 Seiji I, Takashi T, Masato E et al. International Journal of Applied Electromagnetics and Mechanics[J], 2010, 33: 415

11 Ma T Y, Yan M, Zhang J J et al. Rare Metal Materials and Engineering $[\mathrm{J}], 2008,37(4): 869$ (in Chinese)

12 Aphrodite K, Daniele D, Coro V et al. Physica B: Condensed Matter[J], 2014, 435: 25

13 Witold M, Adam W. Archives of Electrical Engineering[J], 2013, 62: 425
14 Krzysztof C, Jan S, Wiesaw W. Journal of Magnetism and Magnetic Materials[J], 2010, 322: 799

15 Bernier N, Leunisa E, Furtadoa C. Micron[J], 2013, 54-55: 43

16 Permiakov V, Dupre L, Pulnikov A et al. Journal of Magnetism and Magnetic Materials[J], 2005, 290-291: 1495

17 Paul H, Andrej S, Oazkar B et al. IEEE Transactions on Industry Applications[J], 2013, 49: 2044

18 Zheng W X, Cheng Z G. IEEE Transactions on Magnetics [J], 2012, 48: 2277

19 Paul H, Doppler C, Anderj S et al. IEEE Transactions on Magnetics[J], 2013, 49: 2033

20 Wang H, Li C S, Zhu T, et al. Acta Metallurgica Sinica[J], 2013, 26(3): 420

21 Cheng Z, Takahashi N, Forghani B et al. IEEE Transactions on Magnetics[J], 2009, 45: 1222

\title{
取向硅钢难磁化方向与磁导率关系的研究
}

\author{
李长生, 王 浩, 朱 涛 \\ (东北大学 轧制技术及连轧自动化国家重点实验室, 辽宁 沈阳 110819)
}

\begin{abstract}
摘 要: 取向电工钢板沿不同方向的磁性能不同, 将取向电工钢板沿与轧向成不同角度剪切成标准的 Epstein 试样并测试其相应的磁学 性能。实验结果表明, 材料的难磁化方向与轧向成 $60^{\circ}$ 角。针对传统的椭圆模型在描述磁导率随磁场强度变化的过程中不准确的问题, 提出了抛物线模型和综合模型用来描述磁导率与磁化角度的关系。当磁场强度大于 $10000 \mathrm{~A} / \mathrm{m}$ 时, 宜采用综合模型; 当磁场强度小于 $10000 \mathrm{~A} / \mathrm{m}$ 时, 宜采用抛物线模型。两阶段关系模型可以准确描述磁导率随磁场强度的变化规律, 对于提高与电工钢相关的电磁计算 有重要的意义, 对电工钢在工业上的更广泛应用意义重大。
\end{abstract}

关键词: 难磁化方向; 取向电工钢; 磁导率模型; 抛物线及综合模型; 磁场强度

作者简介: 李长生, 男, 1964 年生, 博士, 教授, 东北大学轧制技术及连轧自动化国家重点实验室, 辽宁 沈阳 110819, 电话: 024-86387749, E-mail: lics@ral.neu.edu.cn 